\title{
Going Beyond Natural Semantic Metalanguage (NSM) on Culture Evaluation
}

\author{
M Mahyuni* \\ Faculty of Teacher Training and \\ Education \\ University of Mataram \\ Mataram, Indonesia \\ yonmahyuni63@gmail.com
}

\author{
Nur Ahmadi \\ Faculty of Teacher Training and \\ Education \\ University of Mataram \\ Mataram, Indonesia
}

\author{
Muhammad Fadjri \\ Faculty of Teacher Training and \\ Education \\ University of Mataram \\ Mataram, Indonesia
}

\begin{abstract}
Natural Semantic Metalanguage (NSM, henceforth) theory, Wierzbicka $(1994,1997,1999)$, has been claimed to be effective in tackling the cultural semantics phenomena. This is easily proved by using universal semantic primes such as, I, you, say, think, feel, good, and bad. Data in this paper was partly taken from long fieldwork conducted in 2001 and updated until recently through recording and ordinary conversation with those who were/are considered significant. The analysis of the data shows that NSM is insensitive to include the notion of cultural pragmatics which purely accommodates the values built-in in the society. Furthermore, NSM also offers a cognitive explanation without looking at how values work in real social, cultural, and religious circumstances. This is certainly interesting for Sasak in particular as it appears to provide robust phenomena on values in which NSM needs to address. Thus, NSM in turn is expected to be enriched with data from various languages and the values underlying their expressions. Indeed, it is arguable how NSM deals with the particular language socio-pragmatic aspects. This paper takes the perspective that these later notions are the core of semantic realization in every society in which the notion of cultural specificity needs to be taken into account.
\end{abstract}

Key Words: NSM, cultural pragmatics, cognitive explanation, semantic realization

\section{INTRODUCTION}

The seminal work of Wierzbicka [1] 'Natural Semantic Metalanguage (NSM, henceforth), subsequently developed by Wierzbicka and her colleague Goddard $[2,3,4,5,6]$, was based on the principles of clarity and simplicity. According to both of them, an ideal NSM semantic analysis (usually called an EXPLICATION) is a paraphrase composed in the simplest possible terms and therefore avoiding circularity and ambiguity or obscurity. Therefore, NSM has been claimed to be one of the most effective tools to study the issue of socio-cultural values in the world as it is always easy to find out the parallel of the words or phrases being examined.

Both Wierzbicka and Goddard argue that the NSM approach accepts a stringent standard of descriptive adequacy in which all cultural symbols can be substituted without changing the meaning. For instance, by using some simple expressions from ordinary natural language, such as $I$, you, do happen, good, and bad, then those words are believed to have parallel meaning in all languages of the world. This claim seems to be undebatable from logical semantics because it is true that every word can be translated logically into different languages. Unfortunately, this certainly does not work in terms of cultural and religious values. These later notions will be the focus of this paper.

Data in this paper was partly taken from a long Ph.D. fieldwork conducted in 2001 and on regular basis, where necessary, updated until currently. The corpus data was, therefore, mainly gathered through recording and note-taking of ordinary conversations of those who were/are considered significant. Therefore, the notion of 'extensive participation' is relevant in this sense as understanding and information gained appear to be dynamic and in turn, a more comprehensive perspective is acquired. Only relevant data were transcribed and analyzed to meet the need of the claim made in this paper.

This section discusses the Natural Semantic Metalanguage (NSM) theory which has been utilized in some prominent studies in language and culture. The notion of NSM, in its later development called 'cultural script' or 'ethno-pragmatics', has been developed by Wierzbicka's [2, 3, 4] assisted by her colleague Goddard [1, 3, 7]. Wierzbicka [2] in her book CrossCultural Pragmatics asserts:

'It is impossible for a human being to study anything - be it cultures, language, animals or stones - from an extra-cultural point of view... We can find a point of view which is universal and cultural-independent, but we must look for such a point of view not outside all human cultures... but within our own culture, or within any other culture that we are intimately familiar with'.

This argument has been used by Wierzbicka in favor of her NSM, based on a hypothetical system of universal semantic principles, that is, expressed in terms of basic elements such as I, you, want, don't, say, think, feel, good and bad. The advantage of this approach is that 'it avoids arbitrariness either in the formulation of absolutes or in the positioning of relatives' [8]. 
However, Wierzbicka's framework may not be as universal and culture-independent as she argues. [8] indicates that this applies not only to distant languages and cultures but even in two languages as closely related as English and German, based on fairly similar cultures. These closely related languages exhibit substantial differences in the lexical fields. In particular, 'there is a considerable overlap between 'feel' and 'think' two of Wierzbicka's primitives - in the sense of 'consider' in English, but not in German' [8]. This implies that NSM cannot be claimed as a universal approach to study cultural values that exist in all languages. An example from Sasak also suggests that you are not a universal basic element. For instance, Sasak has five $2^{\text {nd }}$ person pronouns: kamu, ante (te), side, pelungguh/pelinggih, dekaji. The use of these forms will depend on the appropriate nature of particular interlocutors, i.e. Кати and ante are used to instruct those in lower status by those considered senior and high status. Side is functioned to address those senior and respected status. While the use of pelungguh and pelinggih signals seniority and those socially respected in status. Dekaji represents the cultural and religious consciousness [9]. Moreover, NSM has been used in an abstract sense, i.e. to describe cultural values based on the ideal concept of a particular language and culture told or reported by its speakers. It is not intended to provide an account of real-life social interactions. In addition, NSM is based on common assumptions about 'what people think' about social interaction and not 'what is happening in real social interactions. Thus, this theory cannot be used to relay a real picture of a particular community in daily communication.

\section{DISCUSSION}

This part is intended to show the insensitivity of NSM universality to handle the case of ethnocentrism, cultural specificity, and religiosity. To start with we refer back to the word primes used above, i.e. I, you, do, feel, good, and bad. However, in this part first and second person pronoun is discussed. Again, to illustrate the case, [9] is adapted.

\section{a. The $1^{\text {st }}$ Person Pronoun}

A key characteristic of the Sasak style is that self-referent should be expressed in a low style [9]. A referent denoting the $1^{\text {st }}$ person in a dyad can be expressed only in 'unmarked' style. For instance, this occurs where the transitive verb beli 'buy' is followed by the object rókóq 'cigarette', as in:

\section{(1) AU: Beliang-kò rókóq \\ buy me cigarette}

'Buy me a cigarette'

This example (1) is acceptable only when uttered according to this formula: for the $1^{\text {st }}$ person, the verb beli 'buy' and its complement rókóq 'cigarette' should be in 'unmarked' style. The clitic kò referring to the $1^{\text {st }}$ person also has the free pronoun equivalent $A k u$, explicitly expressed in dyads, as in beliang aku rókóq 'buy me a cigarette'. There are, however, other possible structural patterns for this example, as illustrated below. In this construction, it is actually possible for the free $1^{\text {st }}$ person pronoun $a k u$ to be replaced by the alus 'polite' pronoun tiang ' $\mathrm{I}$ ', as in:

$$
\begin{gathered}
\text { (2) AU: Beliang tiang rókóq } \\
\text { buy me cigarette } \\
\text { 'Buy me a cigarette'. }
\end{gathered}
$$

Structurally, the following sentences meaning 'buy me a cigarette' are grammatical, but not socially acceptable and therefore, impossible. Thus, neither one's status (noble or commoner), nor age, nor gender has any influence on the form here. However, a change in style yields the $2^{\text {nd }}$ and $3^{\text {rd }}$ person forms indicated below.

\section{b. The $2^{\text {nd }}$ person referent}

As indicated above, speech style in Sasak only makes possible the expression of respect for the addressee or the $3^{\text {rd }}$ person. Respect is expressed in alus words. [9] adds that if the addressee is eligible to receive respect, the distinction is demarcated by the lexical choice. The preceding example, beliangkò rókóq 'buy me a cigarette' can be used to examine the $2^{\text {nd }}$ person referent in the Sasak dyad. There are two possible constructions in use: (1) if the speaker, $\mathrm{AU}$, and the $2^{\text {nd }}$ person referent, RI, are equal in status, then the lexical item for 'cigarette' is in 'unmarked'; and (2) if the addressee is higher, MW, in status than the speaker, the lexical item for both 'buy' and 'cigarette' are in 'marked' tumbas and lanjaran respectively ${ }^{1}$. Example (7) shows the first choice, while example (8) indicates the second possibility.

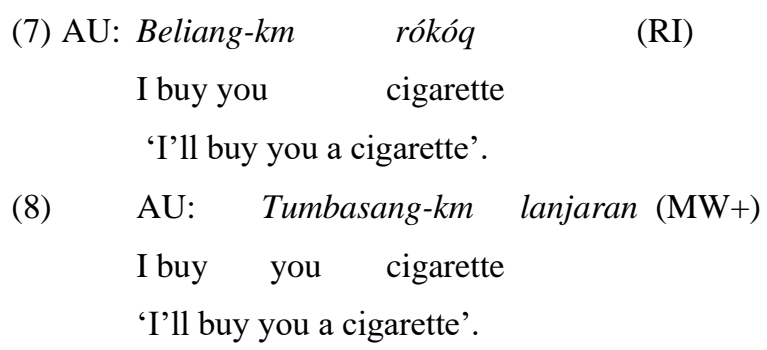

(9) Tumbasang-km rókóq (Socially unacceptable)
I buy you cigarette
'I'll buy you a cigarette'.

(10) Beliang-km lanjaran (Socially
unacceptable)
I buy you cigarette
'I'll buy you a cigarette'.

Example (8) shows that solidarity and intimacy are projected, as it is expressed in 'unmarked' style. No word in this example conveys distance and respect, because the speaker, AU, and referent, RI, are equal in status. In example (8), the speaker, AU, is lower in status than the referent, MW. 
Alternatively, another strategy may be employed where the bound pronoun $\mathrm{km}$ in tumbasang $=\mathrm{km}$ is replaced by the 'marked' style free morpheme to mean the same, as in:

\section{AU: Tiang tumbasang pelungguh lanjaran}

I buy you a cigarette

'I'll buy you a cigarette'.

In brief, the language use for the $2^{\text {nd }}$ person referent depends on the status of the addressee. 'Unmarked' style is used if the both the speaker and the addressee are non- mènak ('noble'), while alus 'high' style is employed if the addressee is mènak. A detailed discussion of the cases is found [9].

An equivalent spirit and principle for deference towards the addressee is observed for Indonesian use of $3^{\text {rd }}$ person pronominal clitic to refer the second person addressee. Such use of pronominal clitic swapping the reference is assigned pragmatically by the need to show respect on the part of the speaker towards the addressee.

\section{Boleh saya minta tandatangannya?}

May $1 \mathrm{sg}$ ask signature-3sg

'would you mind signing my document'

Such use of -nya in a specific setting, between student and lecturer, constitutes a compulsory choice for expressing politeness. A student in such situation is expected to use such pronominal clitic in addressing his or her lecturer in order to get successful and acceptable communication. The use of second person would surely disturb/ annoy the 'face' of the addressee.

\section{c. Social cultural context and challenges to NSM}

Linguistic Expressions in many instances cannot be directly understood without highlighting the socio-cultural context of the language background. Even the idiosyncraticity manifest internal to a language in which dialectal and accentual variation play crucial role. In Sasak, there are at least 5 dialects commonly recognized by the linguists. The dialectal variation is essentially not only about micro linguistic aspect of the language but also concerns with the pragmatic aspect in perceiving the semantic concept in the society. The following illustration concerns with various expression observed in two different dialects representing two different types of society business, Pancor (East Lombok) and Gunungsari (West Lombok) speakers regarding the idea of close friends. In Pancor, in order to refer to the closeness of relationship between friends, we use the word 'kemberasan', a word derived from the rice storage made of bamboo or earth. Kemberasan is a word formed by combining morpheme beras 'rice' and confix expressing nominalization and abstraction affix ke-/-an. Kemberasan is mainly used to save rice for family food reserve. The main function of rice storage is to secure family basic need for the family especially in anticipation of the draught. Because of its vital function for life, kemberasan turns the most essential thing for people's life.
Security of life, in that way, relies much on the security of the kemberasan.

The same idea of showing intimate and closeness in relation, however, is expressed by quite different lexical item by the Kapek Bawah speaker of Gunungsari (meno-mene dialect), gegandek 'pocket'. Gegandek is a word involving partial reduplication of the base gandek 'pocket'. In Sasak the reduplication serves to express plurality 'more than one gandek' and in most practice the reduplication adds the meaning of intensity. This intensity notion implies the degree (intense) relation the speaker wants to express. Thus, the word can be found in real communication either as gandek or gegandek. It could be the case that the use of reduplicative form gegandek relates to and marks the need to show intensity of relation without necessarily implying the plural meaning. A gandek 'pocket' is a kind of small bag which forms part of a piece of clothing, it may also be external of the clothing, and which is used for carrying small things such as money they earn during the market day (Cow/ livestock Trading).

You can use gandek 'pocket' in a lot of different ways to refer to money that people have, get, or spend. Its presence is considered essential in every aspect of lives especially in dealing with their business and other transactional affairs. The presence of the gandek in business concerns may boost the stake holders' convenience on the prospect of the business they are concerned with. The money is thus identical with pocket and in relation to metaphorical expression it surfaces as essential key terms. For example, if someone gives or pays a lot of money, you can say that they gaok gandek 'dig deep into their pocket'. If you approve of something because it is very cheap to buy, you can say ne baruq gandek 'that it suits people's pockets'. It is vital function to store and save money makes gandek the most valuable part of the people's live. It helps secure their account necessary to keep up with the family's daily need. Pancor used to well-known as traditional agricultural society whose main income and earning depends much on their crop, rice field harvests.

The main crops in Pancor is from rice. For security sake, in order to anticipate the shortage of food stock during the dry season when cultivation temporarily stop due to the lack of water supply, the people store the harvest in Lumbung 'a store house'. The harvest in the store house is intended to serve the family's need for the year (farming year period). In the case when the stock surplus, the people take it to the market for trade. If Lumbung is for long period stock, the kemberasan serves to fulfil the family's daily need for consumption. This makes kemberasan overrides the popularity in the people's mind compared to Lumbung. In short, its practical and day to day role in the life of the people's live turns kemberasan the most intimate word in the society.

The frequency and intimate state of kemberasan in the people's life make the word one of the candidate for metaphorical extension. The function of rice in kemberasan to fulfil the daily life consumption structurally extended to the conception of intimacy and closeness. Such conception and perception of the vital and valuable nature of kemberasan (rice) in the mind of the Pancor people promotes the word as 
expression of closeness and intimacy which in turn constitutes structural extension of the thing in the society with their real encyclopaedic situation [10]. Beras 'rice' and kemberasan 'rice box' meets the structure in the society whose daily experience concerns for most with agricultural situation and affair.

The structural condition manifest in the social metaphorical expression is thus directly linked to the living condition of the people. While for Pancor, the word for expression intimacy is rice or the stocks related to agricultural products, the situation manifests itself in quite different expression regarding other society. This is observed for another group of society in Kapek Bawah (Gunungsari, West Lombok). In Kapek Bawah, the word used to express metaphorically the idea of intimate, close relation is gandek. The people in Kapek Bawah relies their living on their commercial business. They are the people whose main business are dealing with the livestock transaction in the local and even national level. Traditional Kapek people brings gandek in every market day. The gandek serves to save their money out of the transaction. Their transaction can hardly be made in the absence of the gandek. Gandek appearance especially in terms of thickness can guarantee the business partners' trust and convenience. It is against such matter of gandek thickness, we observe the word gandek and gegandek to interchange. This perhaps supports the pragmatic notion of intensity of relation based on account (needs further probation). The success of the transaction can thus be predicted through the gandek condition, the thicker the gandek is, the more secure the customer is and the closer the transaction to succeed (security reason). In addition, the gandek can function to attract and establish interrelation with other business partners especially internal to the group and in the society in general. Finally, gandek in the people's perception is conceived as financial security for the family need, and as such it must be secured. At these points, the word gandek finds its way to mark the relation dealing and making in the society.

The people in Kapek Bawah mentions the one who is considered close in their life as gandek 'pocket'. The concept of gandek, the structural property it hold in the interpersonal relation in the society are transferred to the social relation of the people. Close friends and colleagues are perceived in the society as part of individual lives. The availability of close friends contributes to the social security. In addition, the degree of fluidity in the relations determine the sustainability of the social relation. The use of gandek is not in this situation arbitrarily chosen, it is systematically chosen to represent the social structures. Its use to represent close relation meets the structure in the society perception with the living situation in the people's experience. In that way, the use of gandek operates structurally in the sense of Lakoff (2003). The same principle applies for Pancor metaphorical epression 'kemberasan'.

\section{d. NSM's Prototypes Formulation and the local -particular language metaphorical expression}

The comparative data representing the two societies from different dialects in Sasak indicates that metaphorical expression is indeed local and dialect particular. The word gandek and kemberasan are two words which belong to both dialect vocabulary. However, in each dialect, the words come to be realized as separate lexeme in the sense that they are coined as separate semantic unit whose relation to the literal meaning is unrelated to each other. They are used to refer to person with specific emotional quality. Ideally, the words gandek and kemberasan are treated as separate lexical item albeit their metaphorical extension with the literal item. Their treatment as separate lexeme however is blocked by the fact that some metaphorical extension meets the abstract idea of closeness.

With regards to the prototype effort in constructing semantic prime, then there exists a crucial issue related to the metalanguage representation. On the one hand the need to find feature bridging to universality is blocked by the fact that lexical makeup in most instances are directly derived from the socio-cultural states of the speaker. Such socio-cultural states are local and are particularly patterned by specific social merits. Although we may find an idea linking the gandek and kemberasan to closeness, but such closeness are representing quite different motive. In gandek the motifs are related to commercial and quantity base relation, while in kemberasan the nuance is closer to familial and kinship inclusion. Just how these distinctive features in the two social perception be represented in the semantic metalanguage formula makes a crucial issue regarding the universal need of prototypical formula. Furthermore, the data compared are just minority out of the infinite corpus, what would it be if details of crosslanguage data are involved.

\section{CONCLUSION}

It has been admitted that NSM has worked out well to explain or translate cultural values of western society. However, it also has to be representative accommodating data on the Sasak, language spoken by two million people living on the island of Lombok. The data on Sasak first and second person pronouns, as well as Indonesian $3^{\text {rd }}$ pronominal clitic analysed above have shown NSM's methodological and conceptual limitation. In addition, the case of metaphorical extension which specifically relates to the local-particular conceptualization of the speaker regarding their encyclopaedic experience adds further challenges to the invariants and universal claim of NSM. This is certainly interesting as Sasak (or Indonesian) appears to provide robust phenomena on values in which NSM needs to address. Thus, NSM is expected to be enriched with data from various languages and the values underlying their expressions.

\section{REFERENCES}

[1] Wierzbicka, A. (1994). 'Cultural scripts': a new approach to the study of cross-cultural communication, in M Putz (ed.), Language Contact and Language Conflict. Amsterdam: John Benjamins. Pp. 69-87.

[2] Wierzbicka, A. (1991). Cross-cultural pragmatics. Berlin: Mouton de Gruyter.

[3] Wierzbicka, A. (1996). Semantics: primes and universals. Oxford: Oxford University Press.

[4] Wierzbicka, A. (1997). Understanding Cultures through Their Key Words. English, Russian, Polish, German, Japanese. New York: Oxford University Press.

[5] Wierzbicka, A. (1999). Emotions Across Languages and Cultures: Diversity and universals. Cambridge: Cambridge University Press. 
[6] Goddard, C. (1997). Cultural values and 'cultural scripts' of Malay (Bahasa Melayu). Journal of Pragmatics, 27. Pp. 183- 201.

[7] Goddard, C. (2001). Sabar, ikhlas, setia - patient, sincere, loyal?: Contrastive semantics of some 'virtues' in Malay and English.

[8] Clyne, M. G. (1994). Inter-cultural Communication at Work: cultural values in discourse. Cambridge: Cambridge University Press.

[9] Mahyuni (2006). Speech styles and cultural consciousness in Sasak Community. Yayasan CERDAS: Mataram.

[10] Lakoff, George and Mark Johnson, 2003. Metaphors We Live By. United States of America: The University of Chicago (afterword). 